Claremont Colleges

Scholarship@ Claremont

All HMC Faculty Publications and Research

HMC Faculty Scholarship

$1-1-1992$

\title{
Introduction to Sample Calculations
}

Mary P. Cardenas

Harvey Mudd College

\section{Recommended Citation}

Cardenas, Mary P. “Introduction to Sample Calculations," pp. 53-66 in D. Hunzel and D. Huang, Modern Engineering for Design of Liquid-Propellant Rocket Engines, American Institute of Aeronautics and Astronautics, 1992.

This Book Chapter is brought to you for free and open access by the HMC Faculty Scholarship at Scholarship @ Claremont. It has been accepted for inclusion in All HMC Faculty Publications and Research by an authorized administrator of Scholarship @ Claremont. For more information, please contact scholarship@cuc.claremont.edu. 
Chapter 3

\section{Introduction to Sample Calculations}

\subsection{APPROACH}

A primary goal of this book-to familiarize the reader with the detailed techniques used by industiry in liquid-propellant rocket engine systems and component design-has engendered a set of realistic sample calculations. To promote an understanding of the interrelationship among major subsystems, principal calculations have been made for the engines of a hypothetical multistage space vehicle. These calculations and their associated designs were especially prepared for this book and are not related to existing or planned engines. Because the various subsystems of liquid-propellant rocket engines will be discussed in subsequent chapters, most of the supporting sample calculations throughout the book, will be for the engines of the assumed vehicle. For simplicity of reference, the space vehicle will be called Alpha. It will be composed of four stages: A-1, $\mathrm{A}-2, \mathrm{~A}-3$, and A-4. Table 3-1 lists the major parameters of the Alpha.

The Alpha vehicle combines realistic designs, even though not necessarily optimized. For instance, a different propellant combination has been chosen for each stage to permit sample calculations and designs for a number of typical propellant combinations, feed systems, and thrust levels. To permit multiple use of parts, fewer combinations would be chosen. In fact, the student and the teacher using this book may find it interesting and instructive to modify the designs chosen. For instance, the student may wish to determine what engine-design parameters would result if Stages A-2 and A-3 were to use the same propellant combination; or what design parameters would be obtained if Stages A-3 and A-4 were combined into one stage, capable of restart and throttling to $30 \%$ nominal thrust.

It is not our intent to fix a specific mission for Alpha. However, a "primary mission" for it could be the landing of an unmanned scientific payload on the Moon to gather samples and return them to Earth. The staging sequence might then be as follows:

\footnotetext{
Stage A-1: Boost to 250,000-ft altitude.

Stage A-2: Boost to 300-n.mi altitude and inject into Earth parking orbit.

Stage A-3: Accelerate to escape velocity and inject into a translunar trajectory.

Stage A-4: First start-deceleration for lunar orbit and soft Moon landing of scientific payload; second start-Moon takeoff for return to Earth. In addition to its main power plant, Stage A-4 will require very low-thrust attitude control jets.
}

Even if designed for a given "primary mission," a vehicle combination retains a certain degree of
Table 3-1 Four-stage Alpha space vehicle.

Takeoff weight, 2,100,000 lb;

Payloada for 300-n.mi. orbit, 109,500 lb

\begin{tabular}{|c|r|c|c|l|}
\hline Stage & \multicolumn{1}{|c|}{$\begin{array}{c}\text { Stage } \\
\text { Thrust, Ib }\end{array}$} & $\begin{array}{c}\text { Number } \\
\text { of Engines }\end{array}$ & $\begin{array}{c}\text { Engine } \\
\text { Thrust, lb }\end{array}$ & Propellant \\
\hline A-1 & $3,000,000$ & 4 & 750,000 & $\mathrm{LO}_{2} / \mathrm{RP}^{-1}$ \\
A-2 & 600,000 & 4 & 150,000 & $\mathrm{LO}_{2} / \mathrm{LH}_{2}$ \\
A-3 & 48,000 & 3 & 16,000 & $\mathrm{LF}_{2} / \mathrm{LH}_{2}$ \\
A-4 & 15,000 & 2 & 7,500 & $\mathrm{~N}_{2} \mathrm{O}_{4} / \mathrm{N}_{2} \mathrm{H}_{4}$ \\
\hline
\end{tabular}

${ }^{2}$ Consisting of stages 3 and 4 and of the mission payload

flexibility. Within the limits of existing propellanttank configurations, the following principal possibilities of modification exist:

- Omission of the upper two stages for Earth-orbital tankers, shuttle vehicles, space-station assembly, and supply ships.

- Omission of Stage A-4 for unmanned deep-spaceprobe assignments, with no return intended.

- Off-nominal tanking of one or more stages. This modification may yield some overall performance gains for special missions.

Most emphatically, it is not our intent to say that the stated modifications can be made a few days before launch. Rather, the stages and certain of their subsystems - in particular, the engines - should be regarded as building blocks. Their availability can permit meeting a new requirement, for example, within a year, as compared to several years when "starting from scratch." In such ways, substantial gains have been obtained in practice. The earlier Thor, Redstone, and Atlas Mercury boosters are well-known cases.

Brief mention should be made here of experimental engine systems, sometimes referred to as "breadboard" engines. Because of time and funding limitations, the design and development of liquidpropellant rocket engines for a given mission rarely permit the investigation of novel ideas and principles. New ideas must then be tried independently, detached from rigid schedules. Here, the test effort can be conducted with full awareness that many of the principles under investigation will not "make the grade." However, although those that succeed can be applied to advanced operational systems, the marginal ones are just as valuable, because they were prevented from finding their way into operational engines. If experimentally verified advances are selected for operational use with strong emphasis on vehicle application, true progress will have been 
made. The major U.S. liquid-propellant engine manufacturers conducted experimental engine programs with excellent results for a number of years.

The reader will now become acquainted with some of the characteristics of the engines which have been selected for the different stages of the Alpha vehicle. The summarizing descriptions can serve as a guide and reference throughout the book.

\subsection{A-1 STAGE ENGINE}

Four engines, each with 750,000 -lb thrust, were selected for a combined thrust of 3 -million $\mathrm{lb}$, as a compromise between the number of engine systems, and thus complexity, on the one hand, and flexibility, on the other. Flexibility can be gained in different ways, such as including engine-out capabilities using

Table 3-2 A-1 Stage engine operating parameters for sea-level conditions.

\begin{tabular}{|c|c|c|c|c|c|}
\hline \multicolumn{3}{|l|}{ Engine (turbopump feed): } & Line pressure drop & psi & 10 \\
\hline Thrust & $\mathrm{lb}$ & 750,000 & Main valve pressure & psi & 15 \\
\hline Nominal single-firing duration & s & 165 & Calibration orifice pressure drop & psi & 110 \\
\hline Specific impulse & s & 262.4 & Pump: & & \\
\hline Oxidizer $\mathrm{LO}_{2}$ : & & & Inlet pressure & psia & 45 \\
\hline Flow rate & $\mathrm{lb} / \mathrm{s}$ & $1,967.7$ & Discharge pressure & psia & 1,720 \\
\hline Density & $\mathrm{Ib} / \mathrm{t}^{3}$ & 71.38 & Developed pump head & $\mathrm{Ht}$ & 4,790 \\
\hline Fuel RP-1: & & & Pump: & & \\
\hline Flow rate & $\mathrm{lb} / \mathrm{s}$ & 892.3 & Flow rate & $\mathrm{lb} / \mathrm{s}$ & 892 \\
\hline Density & $\mathrm{b} / \mathrm{t}^{3}$ & 50.45 & Shaft power & bhp & 11,790 \\
\hline Mixture ratio & $\mathrm{O} / \mathrm{F}$ & 2.20 & Efficiency & $\%$ & 65.8 \\
\hline \multicolumn{3}{|c|}{$\begin{array}{l}\text { Thrust chamber (tubular wall construction regeneratively } \\
\text { cooled by fuel): }\end{array}$} & $\begin{array}{l}\text { Shaft speed } \\
\text { Turbine: }\end{array}$ & $\mathrm{rpm}$ & 7,000 \\
\hline Thrust & ib & 747,000 & Inlet pressure & psia & 640 \\
\hline Specific impulse & $\mathrm{s}$ & 270 & Inlet temperature & ${ }^{\circ} \mathrm{F}$ & 1400 \\
\hline Injector end pressure & psia & 1,095 & Pressure ratio & & 23.7 \\
\hline Nozzle stagnation pressure & psia & 1,000 & Gas flow rate & $\mathrm{lb} / \mathrm{s}$ & 92 \\
\hline Oxidizer flow rate & $\mathrm{lb} / \mathrm{s}$ & 1,941 & Shaft power & bhp & 27,140 \\
\hline Fuel flow rate & $\mathrm{lb} / \mathrm{s}$ & 827 & Efficiency & $\%$ & 58.2 \\
\hline Mixture ratio & $\mathrm{O} / \mathrm{F}$ & 2.35 & Shaft speed & $\mathrm{rpm}$ & 7,000 \\
\hline$c^{*}$ efficiency & $\%$ & 97.5 & Shaft torque & in $-1 b$ & 20,380 \\
\hline$c^{*}$ & $\mathrm{It} / \mathrm{s}$ & 5,660 & Auxiliary drive: & & \\
\hline$C_{\text {f }}$ efficiency & $\%$ & 98 & Shaft power & bhp & 500 \\
\hline$c_{1}$ & & 1.532 & Gas generator system: & & \\
\hline Contraction ratio & $A_{c} / A_{t}$ & 1.6 & Oxidizer side: & & \\
\hline Expansion ratio & $A_{\theta} / A_{t}$ & 14 & Flow rate & $\mathrm{lb} / \mathrm{s}$ & 26.7 \\
\hline Throat area $\mathrm{A}_{t}$ & in 2 & 487 & Entrance loss & psi & 25 \\
\hline$L^{*}+1$ & in. & 45 & Line pressure drop & psi & 25 \\
\hline Nozzle contour & & $80 \%$ bell & Control-orifice pressure drop & psi & 615 \\
\hline Oxidizer side: & & & Valve pressure drop & psi & 10 \\
\hline Injector pressure drop & psi & 200 & Injector pressure drop & psi & 120 \\
\hline Torus dome pressure drop & psi & 150 & Fuel side: & & \\
\hline Line pressure drop & psi & 25 & Flow rate & $\mathrm{lb} / \mathrm{s}$ & 65.3 \\
\hline Main valve pressure drop & psi & 35 & Entrance loss & psi & 25 \\
\hline Pump inlet pressure & psia & 55 & Line pressure drop & psi & 25 \\
\hline Pump discharge pressure & psia & 1,505 & Control-orifice pressure drop & psi & 800 \\
\hline Developed pump head & $\mathrm{Ht}$ & 2,930 & Valve pressure drop & psi & 20 \\
\hline Pump: & & & Injector pressure drop & psi & 140 \\
\hline Flow rate & $\mathrm{lb} / \mathrm{s}$ & 1,971 & Gas generator: & & \\
\hline Shaft power & bhp & 14,850 & Mixture iatio & O/F & 0.408 \\
\hline Efficiency & $\%$ & 70.7 & Injector end pressure & psia & 710 \\
\hline Shatt speed & $\mathrm{rpm}$ & 7,000 & Combustor pressure drop & psi & 70 \\
\hline Heat exchanger & $\mathrm{lb} / \mathrm{s}$ & 3 & Thrust vector control: & & \\
\hline Fuel side: & & & Minimum acceleration & $\mathrm{rad} / \mathrm{s}^{2}$ & 1 \\
\hline Injector pressure drop & psi & 200 & Maximum velocity & $\operatorname{deg} / \mathrm{s}$ & 10 \\
\hline Jacket and manifold pressure drop & psi & 270 & Displacement & deg & \pm 14 \\
\hline
\end{tabular}


smaller systems or designs already in existence and implementing various guidance (gimballing) and packaging considerations.

The propellant combination of liquid oxygen (LOX) and kerosene-type RP-1 fuel was selected for the A-1 engine, principally because high performance will not be as critical for booster first stages as for upper stages. Moreover, both propellants are abundantly available and comparatively inexpensive; the fluids and their combustion products are "docile"; their corrosivity is nil. Both fluids are relatively dense. Liquid-propellant rocket engine systems using these propellants are well developed and reliable, and thus many "off the shelf" components and designs are available for them.

\section{General Engine-System Description}

The A-1 engine is a single-start, fixed-thrust, gimballed, bipropellant system. The fuel, RP-1, is also used as the turbopump lubricant and as the enginecontrol-system actuating fluid. The major components of the A-1 engine are a regeneratively-fuelcooled, double-pass, tubular-wall thrust chamber with bolt-on injector; a direct-drive turbopump consisting of two centrifugal pumps and a single-stage, two-wheel turbine; an uncooled gas generator with a dual-ball valve; butterfly main valves; and the required controls. The gas generator uses the same propellant combination as the thrust chamber. Table 3-2 presents all necessary operating parameters on which engine component designs will be based for the A-1 engine system.

Figure 3-1 shows the A-1 engine schematic, which identifies clearly all major engine components and their interconnecting plumbing. For the various phases of engine design and development, it has been found useful to work from an "engine-performance diagram," a combination of the basic engine schematic and the principal performance parameters. The A-1 engine diagram is shown in Fig. 3-1. (We suggest that the readers prepare their own performance diagrams for the other three stages.)

For compactness and simplicity of mounting, the turbopump is attached directly to the thrust chamber. All other components either are mounted on these two assemblies or are located in the plumbing system between them. This arrangement permits engine gimballing without pump-discharged, high-pressure propellant-duct flexure. Instead, thrust-vector control is achieved by gimballing the entire engine. The engine weighs approximately $7500 \mathrm{lb}$ dry, $7900 \mathrm{lb}$ wet, and $7830 \mathrm{lb}$ at burnout. The preliminary design layout of the A-1 engine system and its overall dimensions are presented in Fig. 3-2.

\section{System Operation}

For starting, the A-1 engine employs a "main-tankhead start" approach, combined with a pressureladder sequence. Propellants are used under vehicle tank-head pressures to initiate gas-generator operation. As the turbopump starts to accelerate, main propellant pressures "bootstrap" the system to mainstage level.
Starting sequence. As shown in Figs. 2-20 and 2-21 (pages 45 and 46), launch preparations completed and the main propellant tanks pressurized, the gas-generator's dual spark plugs are activated upon a given signal, and the engine four-way control valve is energized to open. The closing side is vented, and fuel-pump outlet pressure ( 50 psia from tank head) is admitted to the opening side of the main oxidizer and the gas-generator valve actuators. The gasgenerator valves open and admit both propellants to the gas-generator combustor, where they are ignited by the spark plugs. At this point, the main oxidizer valve remains closed; the valve spring prevents it from opening until later in the sequence, when substantially higher actuating fuel pressures are developed by the pump.

The initial, low power level of the gas generator is sufficient to start and accelerate the turbopump. This acceleration, in turn, increases the propellant pressures available to the gas generator, which is connected upstream of the still-closed main fuel and oxidizer valves. As a result, the gas-generator turbine system "bootstraps" itself.

At a predetermined fuel-pump outlet pressure (valve-spring rate selection), the main oxidizer valve opens, During the oxidizer-valve stroke, an integral and mechanically linked igniter fuel-sequence valve is actuated. The sequence valve then admits pressurized fuel to a hypergol igniter cartridge, rupturing its diaphragms. Hypergol (such as triethylaluminum) enters the combustion-chamber igniter elements and ignites with the oxidizer (which is just being admitted by the main oxidizer valve). The fuel following the hypergol sustains the igniter flame.

The chamber pressure which results from igniter combustion is sufficient to actuate the ignitionmonitor valve. This valve admits fuel pressure to the actuator that opens the main fuel valve, the last step in the sequence. As the main fuel enters the combustion chamber, the chamber pressure and thrust climb to the rated level.

Cutoff sequence. As shown in Figs. 2-20 and 221 , a cutoff signal de-energizes, and thus closes the engine four-way control valve. The opening pressures of all valves vent; the valves close. Turbine power and main-chamber pressure decay. While the main propellant tanks vent, all valves are held in the closed position by springs. Note that the gasgenerator valve and the main oxidizer valve are closed by admitting actuation pressure to their closing port, but the main fuel valve is closed by spring force only. Experience has shown that cutoff precision is largely influenced by turbopump decay characteristics and by cessation of the propellant flow that has the smallest duct volume below the valve - in this case, the oxidizer (with no cooling jacket). The fast-closing valves need some timing, however, to control pressures caused by waterhammer effects.

\subsection{A-2 STAGE ENGINE}

For the same reasons as with the first stage, the A-2 will have clustered (four) engines, delivering vacuum thrust of $600,000 \mathrm{lb}(150,000 \mathrm{lb}$ per engine). Because 


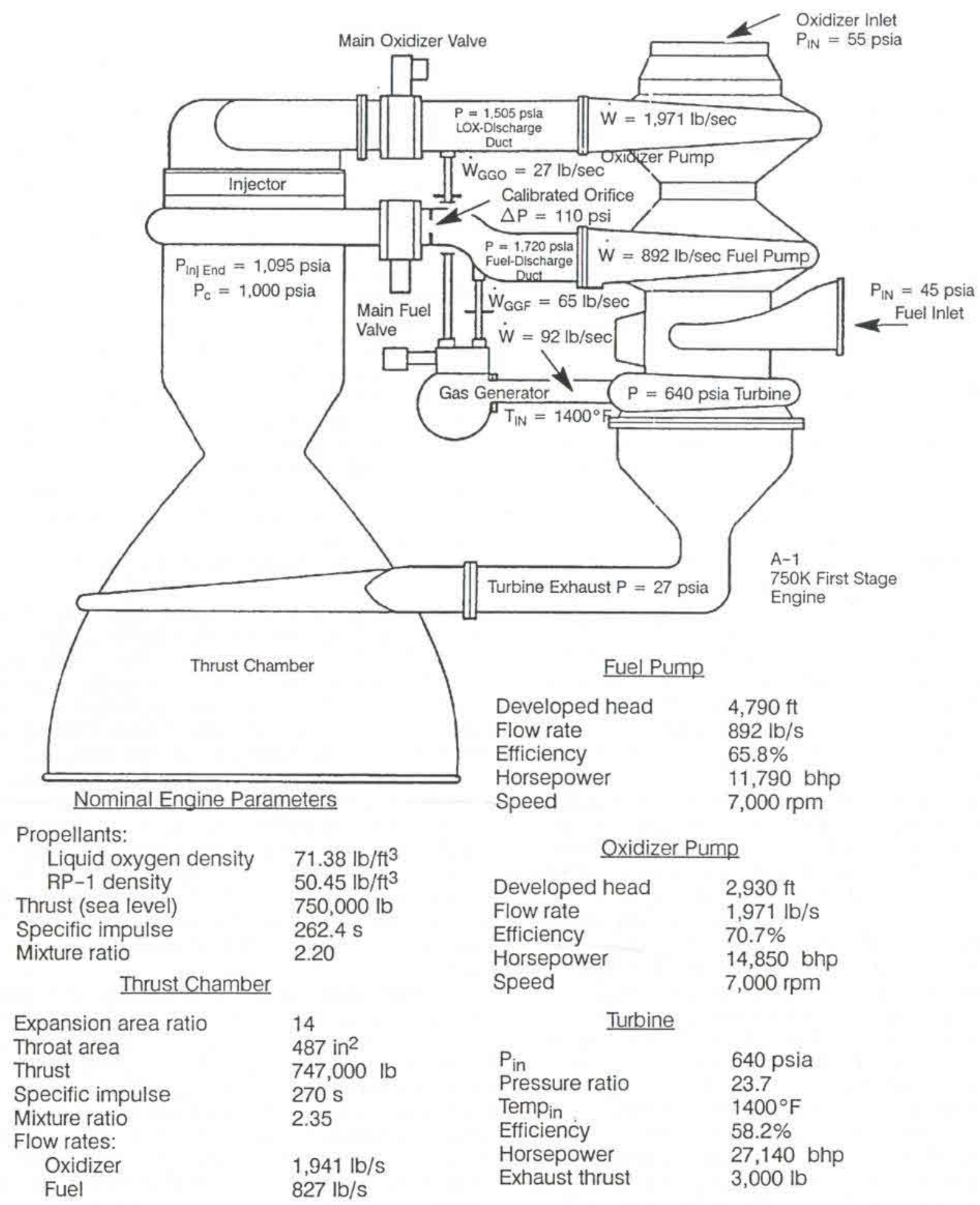

Fig. 3-1 A-1 engine performance diagram.

of the substantial performance gains obtainable through the use of high-energy propellants in upper stages, liquid oxygen/liquid hydrogen $\left(\mathrm{LOX} / \mathrm{LH}_{2}\right)$ have been selected as propellants.

Over the years, the production and handling of the cryogenics liquid oxygen and liquid hydrogen have become routine; and the price has come down considerably. Both elements are abundantly available. Their combustion product - water vapor - is the most harmless of all propellant exhausts, solid or liquid. Telemetry engineers like it because of its low attenuation of RF signals, an important aspect for vehicle guidance and telemetry. Most important, the yield in specific impulse of this combination approaches theoretical maximum for chemical reactions. Only certain fluorine/hydrogen combinations are slightly higher (approximately 4\%). (The extreme toxicity of fluorine and fluorine compounds, both as liquids and as components of combustion products, makes fluorine less attractive for operational use.) By building the A-1 and A-2 stages a little larger, the same payload that fluorine offers can be obtained. 

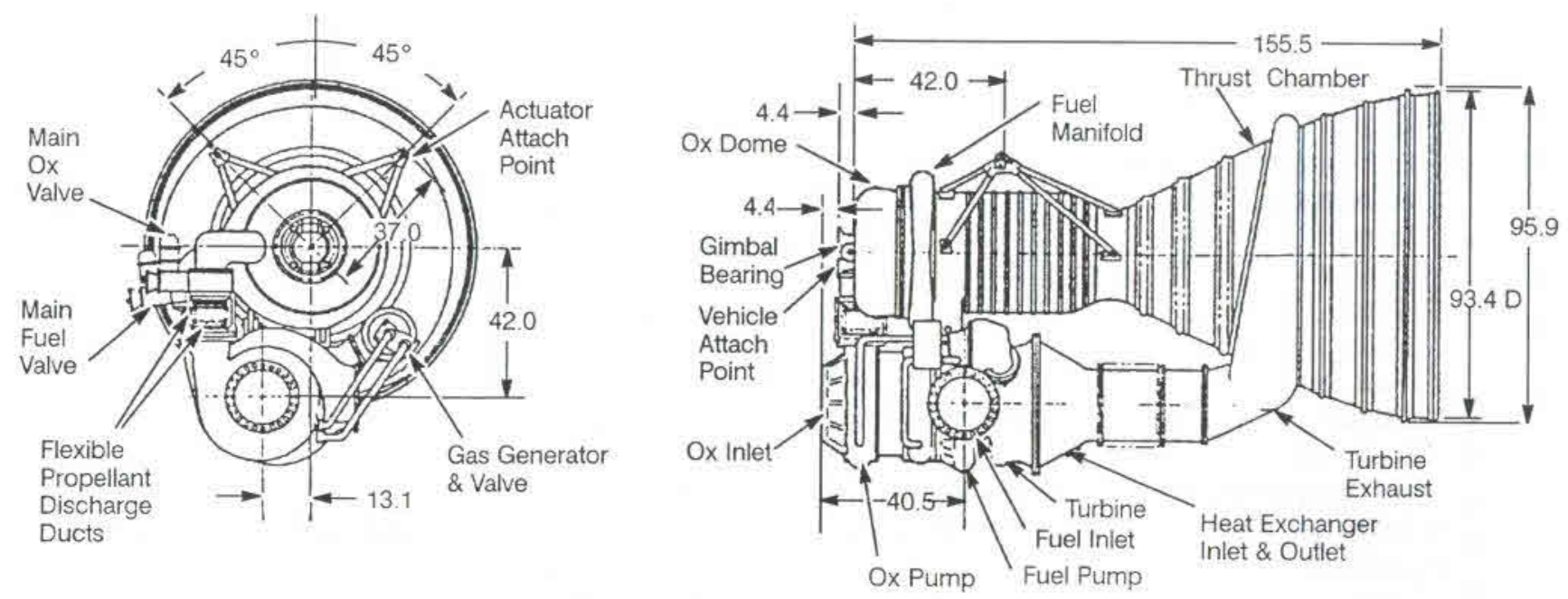

Fig. 3-2 Preliminary layout of A-1 first-stage engine system.

Moreover, all the advantages of $\mathrm{LOX} / \mathrm{LH}_{2}$ are retained, including the extensive past experience with them.

Even so, hydrogen does have its drawbacks, the principal one being its low density, resulting in rather bulky tanks, which make it an unattractive candidate for first-stage/booster applications in most cases. For a typical oxygen-to-hydrogen mixture ratio of $5: 1$, the corresponding volume ratio is inversed: $1: 5$. This disadvantage, however, will be offset for upper stages by the high-energy yield $\left(\mathrm{I}_{\mathrm{S}}\right)$. The improved state of the art of ultralightweight vehicle and tank constructions will further increase the superiority of hydrogen for upper stages.

Low density also creates a high boiloff rate, unless tanks and lines are properly insulated. Because of the low density and the resulting large surface area of the containers, the heat input per unit of hydrogen mass is high. Furthermore, the temperature of liquid hydrogen is sufficiently low to liquefy air on tank surfaces. This liquefaction sharply increases heattransfer rates, resulting in extreme boiloff rates. Tankand-line insulation, therefore, is vital. Although the techniques of rocket-vehicle insulation are highly developed, the necessary insulation does impose some weight penalties.

Overall, however, hydrogen produces a substantial net performance gain for upper stages.

\section{General Engine-System Description}

The A-2 engine is a single-start, fixed-thrust, gimballed, bipropellant system. The thrust chamber features a combination of fuel regenerative cooling and film cooling with turbine exhaust gas. The chamber assembly is fed by two independent, direct-drive centrifugal turbopumps. For the fuel, an alternative axial pump may be chosen. Each operates at optimum speed. Hot gases are tapped off the main combustion chamber to power the turbines. A hot-gas orifice in the tapoff duct controls the engine thrust level. The turbines, gas-coupled in parallel, exhaust to the thrust chamber, being injected in the 30:1expansion-area-ratio plane. Thus, the gases provide film cooling for the nozzle portion and from there to the 40:1-area-ratio plane. The remainder of the chamber, upstream of the $30: 1$ plane, is regeneratively cooled (1 $1 / 2$ pass). Helium gas actuates the controls. No lubricants and no fluids that could freeze at low temperatures are used. Hot gases generated by a solid-propellant turbine spinner start the engine. Chlorine trifluoride $\left(\mathrm{CIF}_{3}\right)$, hypergolic with $\mathrm{LH}_{2}$, ignites the combustion chamber. The turbine spinner and igniter fluid are both insulated and temperatureconditioned electrically from a ground source until first-stage takeoff. Gaseous hydrogen bled from the thrust-chamber coolant passage pressurizes the mainfuel tank. A small portion of liquid oxygen, bled from the oxidizer-pump discharge and heated in a heat exchanger, pressurizes the main oxidizer tank .

Table 3-3 lists the A-2 engine operating parameters. The engine schematic diagram appears in Fig. 33. Note that engine parameters are based on vacuum conditions-because A-2 starts and operates in a vacuum for its entire duration. In the case of the A-2 Stage, the starting altitude of $250,000 \mathrm{ft}$ can be considered absolute vacuum, for all practical purposes.

Gimballing the entire engine applies TVC. The engine weighs approximately $2181 \mathrm{lb}$ dry, $2317 \mathrm{lb}$ wet, and $2292 \mathrm{lb}$ at burnout. The overall dimensions and the preliminary design layout of the A-2 engine are shown in Fig. 3-4.

\section{System Operation}

The A-2 engine (Fig. 3-3 and 3-5) employs a "turbine spin start" for very fast buildup (less than $2 \mathrm{~s}$ from start signal to main stage). Starting power is furnished by a turbine spinner. Chamber tapoff gases then bootstrap the turbine.

\section{Starting Sequence}

As part of the separation and staging sequence, a vehicle programmer furnishes a start signal (to the engine) that ignites the turbine spinner, which supplies gases at $2000^{\circ} \mathrm{F}$ to the turbines and combustion chamber. This signal also energizes the solenoid of the engine control valve that vents the closing side of both main propellant-valve actuators and 
Table 3-3 A-2 Stage engine operating parameters for vacuum conditions.

\begin{tabular}{|c|c|c|c|c|c|}
\hline \multicolumn{3}{|l|}{ Engine (turbopump feed): } & \multirow{2}{*}{$\begin{array}{l}\text { Shaft speed } \\
\text { Turbine: }\end{array}$} & \multirow[t]{2}{*}{$\mathrm{rpm}$} & \multirow[t]{2}{*}{8,600} \\
\hline Thrust & Ib & 150,000 & & & \\
\hline Nominal single-firing duration & s & 250 & Inlet pressure & psia & 700 \\
\hline Specific impulse & s & 434 & Inlet temperature & ' $\mathrm{F}$ & 1200 \\
\hline Oxidizer $\mathrm{LO}_{2}$ : & & & Pressure ratio & & 16 \\
\hline Flow rate & $\mathrm{lb} / \mathrm{s}$ & 288 & Gas flow rate & $\mathrm{lb} / \mathrm{s}$ & 1.58 \\
\hline Density & $\mathrm{Ib} / \mathrm{t}^{3}$ & 71.38 & Shaft power & bhp & 1,940 \\
\hline Fuel $\mathrm{LH}_{2}$ : & & & Efficiency & $\%$ & 54.3 \\
\hline Flow rate & $\mathrm{lb} / \mathrm{s}$ & 57.6 & Shaft speed & $\mathrm{rpm}$ & 8,600 \\
\hline Density & $\mathrm{Ib} / \mathrm{t}^{3}$ & 4.42 & Shaft torque & in-lb & 14,200 \\
\hline Mixture ratio & O/F & 5 & Fuel side: & & \\
\hline \multirow{3}{*}{\multicolumn{3}{|c|}{$\begin{array}{l}\text { Thrust chamber (tubular wall construction regeneratively } \\
\text { cooled by fuel. Nozzle extension film cooled by turbine } \\
\text { exhaust gas): }\end{array}$}} & Injector pressure drop & psi & 100 \\
\hline & & & Jacket and manifold pressure drop & psi & 325 \\
\hline & & & Line pressure drop & psi & 20 \\
\hline Thrust & $\mathrm{lb}$ & 149,500 & Main valve pressure drop & psi & 20 \\
\hline Specific impulse & s & 440 & Calibration orifice pressure drop & psi & 60 \\
\hline Injector end pressure & psia & 875 & Pump inlet pressure & psia & 25 \\
\hline Nozzle stagnation pressure & psia & 800 & Pump discharge pressure & psia & 1,400 \\
\hline Oxidizer flow rate & $\mathrm{lb} / \mathrm{s}$ & 285.2 & Developed pump head & $\mathrm{ft}$ & 44,800 \\
\hline Fuel flow rate & $\mathrm{lb} / \mathrm{s}$ & 54.5 & Pump weight flow rate & $\mathrm{lb} / \mathrm{s}$ & 59.8 \\
\hline Mixture ratio & O/F & 5.22 & Pump volumetric flow rate & gpm & 6,080 \\
\hline$c^{*}$ efficiency & $\%$ & 97.5 & Heat exchanger bleed & $\mathrm{lb} / \mathrm{s}$ & 2.2 \\
\hline$c^{*}$ & $\mathrm{ft} / \mathrm{s}$ & 7,480 & Pump: & & \\
\hline $\mathrm{C}_{f}$ efficiency & $\%$ & 101 & Shaft power & bhp & 6,100 \\
\hline$C_{f}$ & & 1.895 & Efficiency & $\%$ & 80 \\
\hline Contraction ratio & $A_{c} / A_{t}$ & 1.60 & Shaft speed & rpm & 27,000 \\
\hline Expansion ratio & $A_{e} / A_{t}$ & 40 & \multicolumn{3}{|l|}{ Chamber coolant passage bleed } \\
\hline Throat area A & in ${ }^{2}$ & 98.6 & for fuel tank pressurization & $\mathrm{lb} / \mathrm{s}$ & 2.2 \\
\hline$L^{*}+\quad$ & in. & 26 & \multicolumn{3}{|l|}{ Turbine: } \\
\hline Nozzle contour & & $75 \%$ bell & Inlet pressure & psia & 700 \\
\hline \multicolumn{3}{|l|}{ Oxidizer side: } & Inlet temperature & ${ }^{\circ} \mathrm{F}$ & 1200 \\
\hline Injector pressure drop & psi & 160 & Pressure ratio & & 16 \\
\hline Torus dome pressure drop & psi & 40 & Gas flow rate & $\mathrm{lb} / \mathrm{s}$ & 4.32 \\
\hline Line pressure drop & psi & 20 & Shaft power & bhp & 6,100 \\
\hline Main valve pressure drop & psi & 20 & Efficiency & $\%$ & 62.5 \\
\hline Calibration orifice pressure drop & psi & 60 & Shaft speed & rpm & 27,000 \\
\hline Pump inlet pressure & psia & 35 & Shaft torque & in-lb & 14,250 \\
\hline Pump discharge pressure & psia & 1,175 & \multicolumn{3}{|c|}{ Tapoff gas from thrust chamber for turbine drive: } \\
\hline Developed pump head & $\mathrm{ft}$ & 2,305 & Pressure & $\mathrm{lb} / \mathrm{in}^{2}$ & 750 \\
\hline Pump weight flow rate & $\mathrm{lb} / \mathrm{s}$ & 290.5 & Temperature & ${ }^{\circ} \mathrm{F}$ & 1200 \\
\hline Pump volumetric flow rate & gpm & 1,830 & Weight flow rate & $\mathrm{lb} / \mathrm{s}$ & 5.9 \\
\hline \multicolumn{3}{|l|}{ Heat exchanger bleed (oxidizer } & Mixture ratio & O/F & 0.90 \\
\hline tank pressurization) & $\mathrm{lb} / \mathrm{s}$ & 2.5 & \multicolumn{3}{|l|}{ Thrust vector control: } \\
\hline Pump: & & & Minimum acceleration & $\mathrm{rad} / \mathrm{s}^{2}$ & 2 \\
\hline Shaft power & bhp & 1,910 & Maximum velocity & $\mathrm{deg} / \mathrm{s}$ & 15 \\
\hline Efficiency & $\%$ & 64 & Displacement & $\operatorname{deg}$ & \pm 6 \\
\hline
\end{tabular}

pressurizes the opening side of the fuel-valve actuator with helium gas. Simultaneously, the hypergolsequence valve (mechanically linked to the main fuel valve), is opened and the actuator of the (normally open) fuel-bleed valve is pressurized closed. The fuel flows through the chamber cooling jacket under increasing pump-discharge pressure and injects into the combustion chamber. Ignition is achieved by the hypergolic reaction between hydrogen and the slug of chlorine trifluoride forced into the chamber by increased oxidizer-pump discharge pressure.
When the main fuel valve reaches the 90\%-open position, ports open that are integral with the actuating piston and permit helium gas to flow through the hypergol-monitor valve and to pressurize the open side of the main oxidizer-valve actuator. The main oxidizer valve opens, admitting oxidizer to the chamber where pressure builds up rapidly. Chamber tapoff gases bootstrap the turbines to mainstage operation. The spinner burns for about $1.2 \mathrm{~s}$. After the main stage level is achieved, the propel-lant-utilization servo system begins to function. 


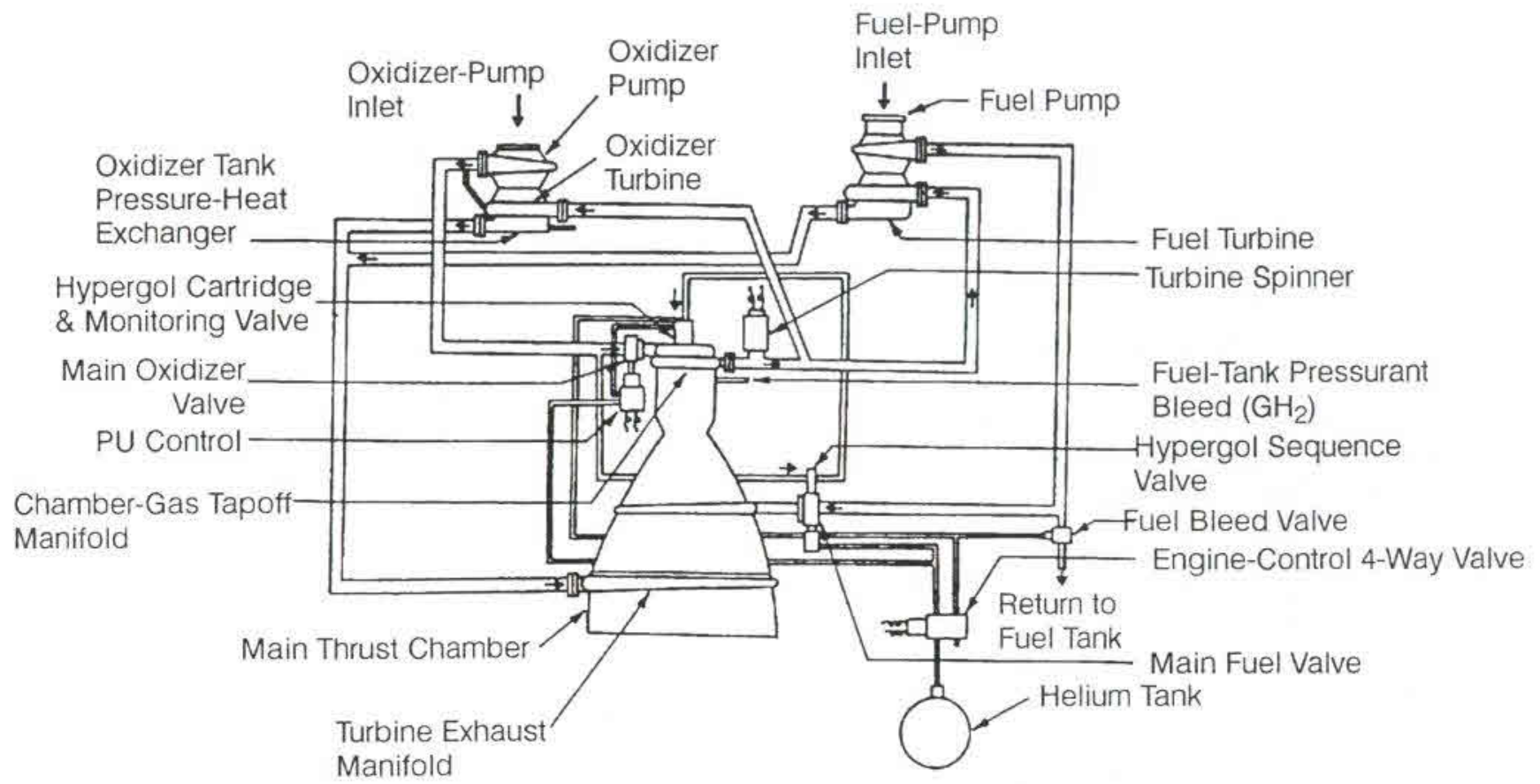

Fig. 3-3 A-2 Stage engine-system schematic diagram.

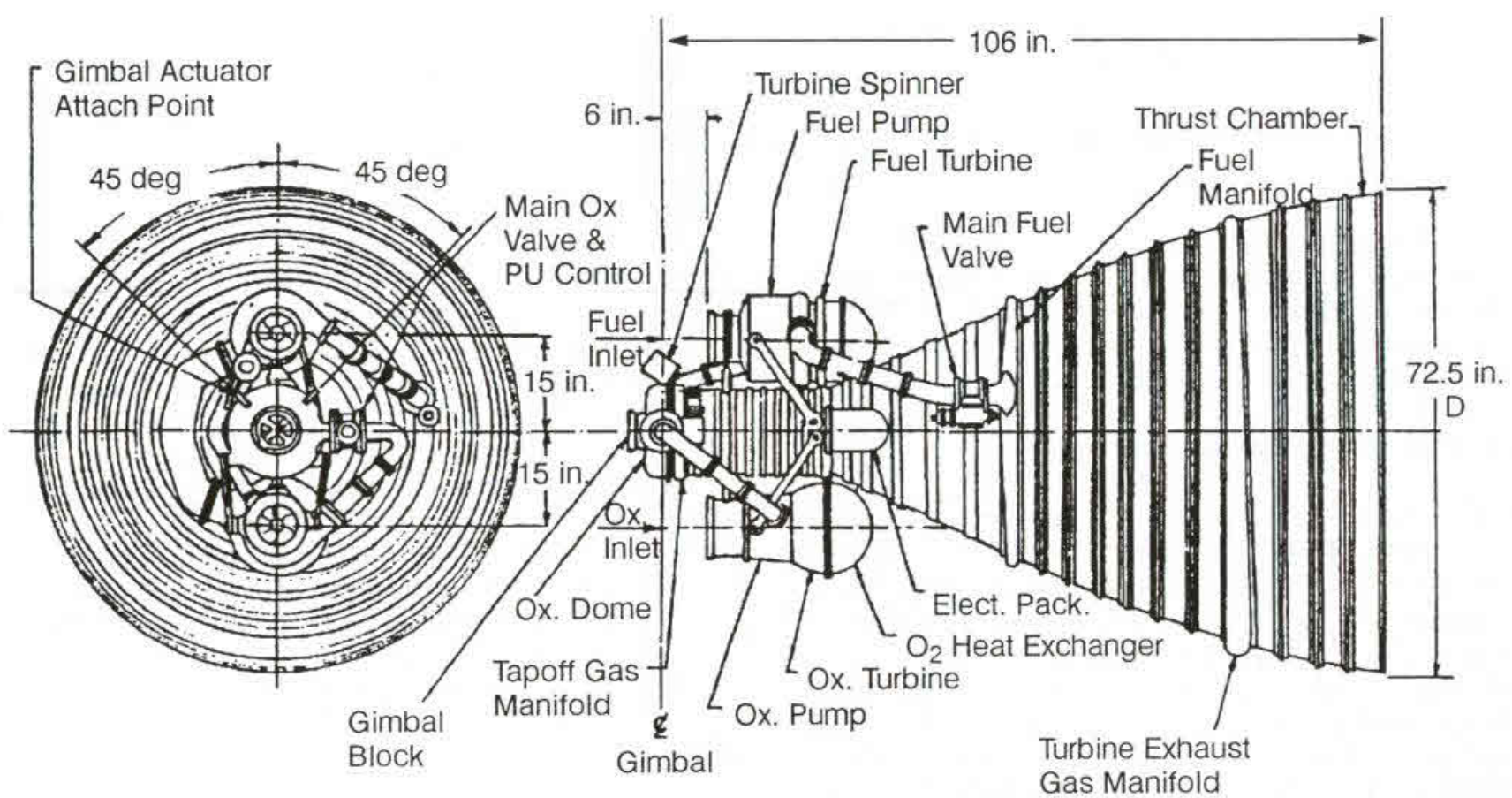

Fig. 3-4 Preliminary layout of A-2 Stage engine system.

\section{Cutoff Sequence}

The cutoff signal, received from the vehicle programmer, de-energizes the engine-control valve causing it to close. This closure vents the open side and pressurizes the closing side of the main propellant-valve actuators. By proper orificing of the helium lines, the main oxidizer valve is made to close faster than the main fuel valve, to ensure a fuel-rich cutoff. The valve closure causes engine thrust to decay. The fuel bleed valve opens after venting of the helium pressure in its actuator.

\subsection{A-3 STAGE ENGINE}

Three engines of 16,000 -lb thrust each power the A-3 Stage. They employ liquid fluorine and liquid hydrogen as propellants to gain the very high performance required of upper stages. To date, there have been almost no applications of fluorine as a propellant except on an experimental basis. Fluorine has vigorous and reliable hypergolic ignition and superior specific impulse with most fuels. The high density of liquid fluorine, combined with high performance with liquid hydrogen, results in maximum payloads. It 

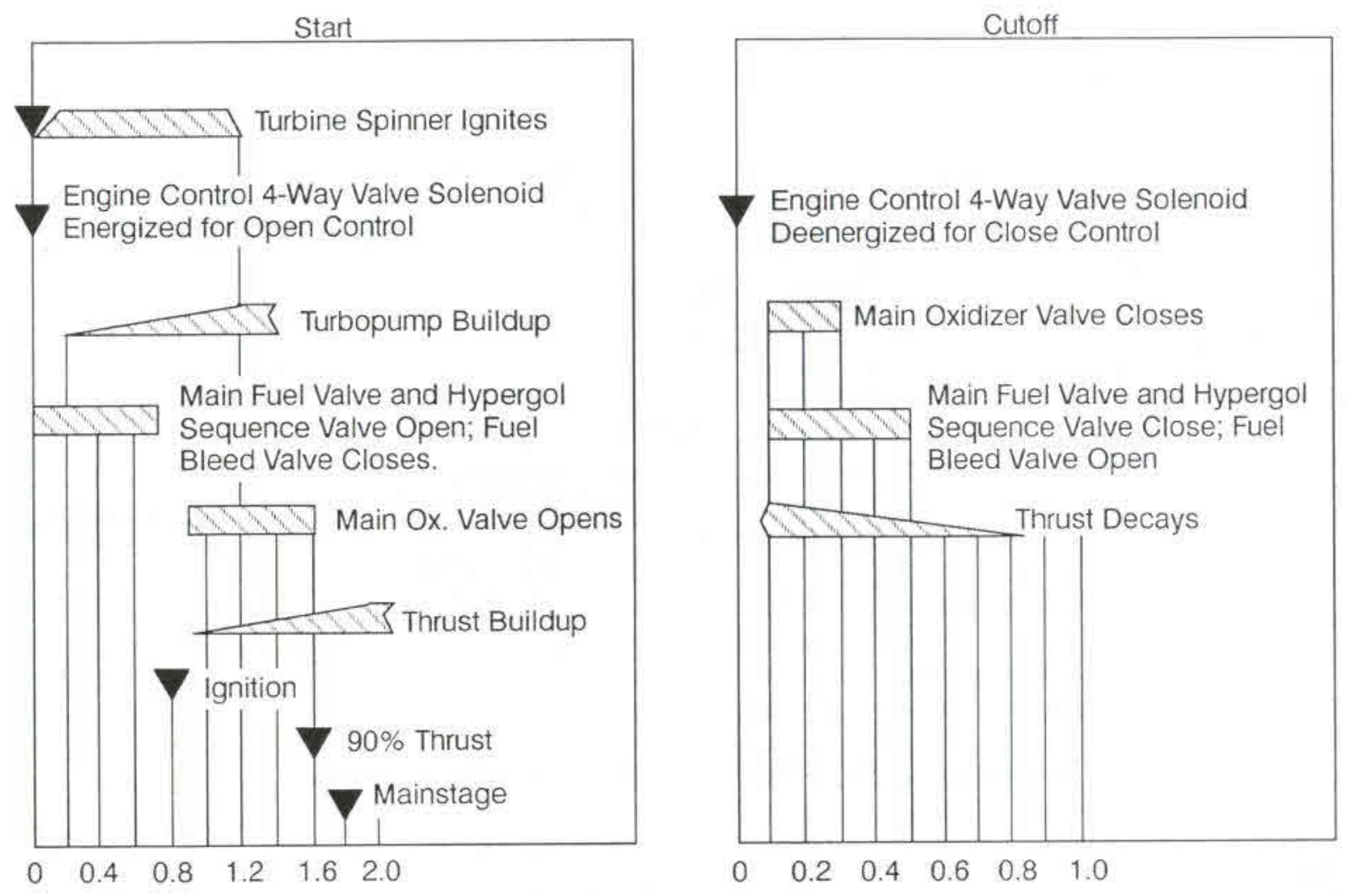

Fig. 3-5 A-2 Stage engine-system sequence diagram.

has been thought that as mis-sion requirements become more ambitious, payload advantages from the fluorine-oxidized propellant combination might compensate for handling problems caused by fluorine toxicity and corrosiveness.

\section{General Engine-System Description}

The A-3 engine is a multiple-start, gimballed, bipropellant system. The thrust chamber uses a combination of fuel-film $\left(\mathrm{LH}_{2}\right)$ and radiation cooling. The propellants are fed directly from pressurized propellant tanks, through main propellant valves, to thrust-chamber inlets. The propellant tanks and their gas pressurization system are considered part of the engine propellant-feed system. Gaseous helium, supplied from a high-pressure helium bottle located inside the main fuel tank, pressurizes the main oxidizer tank. The main fuel tank is pressurized by gaseous hydrogen, supplied from a liquid-hydrogen bottle pressurized by helium; it is located inside the main fuel tank. Both pressurants are heated in heat exchangers, located at the thrust-chamber nozzle extensions, before being expanded through pressure regulators and transferred to the propellant tanks. Helium gas operates the main valves and the gimbal actuators and purges the propellant manifolds during the hypergolic start.

Table 3-4 lists A-3 engine operating parameters for vacuum conditions. Figure 3-6 shows the propulsion system schematic diagram.

The highly reactive and toxic nature of fluorine forces simplicity and a minimum number of com- ponents in design of the entire propulsion system. Welded joints are used extensively. No rotating seals are employed; sliding seals, the metal-bellows type.

A preliminary design layout of the A-3 propulsion system and its dimensions are depicted in Fig. 37. The fuel tank is pressure- rather than mechanically stabilized. The thrust loads are transmitted to the payload through the fuel tank. Both tanks are insulated, along with the ducts between tanks and engine systems. Gimballing the thrust chambers applies TVC. Each basic engine weighs approximately $330 \mathrm{lb}$ dry and $365 \mathrm{lb}$ at burnout. Each has a cylindrical space envelope of $5 \mathrm{ft} 4 \mathrm{in}$. in diam by $7 \mathrm{ft} 6$ in. in length. The propulsion system (including the three engines and the tankage) weighs approximately 5130 $\mathrm{lb}$ dry, $37,900 \mathrm{lb}$ wet, and $5530 \mathrm{lb}$ at burnout.

\section{System Operation}

The A-3 propulsion system is designed for automatic start on receiving a signal from the guidance system. A similar signal starts automatic engine shutdown. One or more restarts can be made by merely sending additional start/shutdown signals to the propulsion system. Figure 3-8 shows the operational sequence of the A-3 engine stage. In conjunction with Fig. 3-6, this figure illustrates the startup and shutdown of the system.

\subsection{A-4 STAGE ENGINE}

The A-4 stage employs two engines, each of $7500-1 \mathrm{~b}$ thrust, to achieve a desired thrust of $15,000 \mathrm{lb}$. It is as- 
sumed that the mission assigned to this fourth (and last) stage of the space vehicle may require prolonged cruising periods before ignition and possibly even longer waiting periods before re-ignition. Although it would be desirable to utilize the high-energy propellants of the second and third stages, the fact that they are cryogenics poses some problems. Cryogenic propellants could probably be used with refined insulation techniques, but they were not selected because the increase in complexity (resulting from the insulation techniques) was deemed inappropriate for a vehicle of this size. Solid propellants were also ruled out because of the requirement for repeated starts and throttling.
Storable hypergolics possess certain characteristics that contribute to high reliability-such as simplicity of ignition and ease of propellant maintenance (because the propellants can be contained in closed vessels over reasonable temperature ranges for considerable periods of time without developing excessively high pressures or undergoing unacceptable changes in composition). Applicable storables with high performance include chlorine trifluoride $\left(\mathrm{CIF}_{3}\right)$ /hydrazine $\left(\mathrm{N}_{2} \mathrm{H}_{4}\right)$ and nitrogen tetroxide $\left(\mathrm{N}_{2} \mathrm{O}_{4}\right) / \mathrm{N}_{2} \mathrm{H}_{4}$. As a monopropellant, hydrazine is prone to explosive thermal decomposition, but this condition can be remedied by certain additives. The $\mathrm{CIF}_{3} / \mathrm{N}_{2} \mathrm{H}_{4}$ produces slightly higher performance

Table 3-4 A-3 Stage engine operating parameters for vacuum conditions.

\begin{tabular}{|c|c|c|c|c|c|}
\hline \multicolumn{3}{|l|}{ Engine (pressurized gas-feed): } & Calibration orifice pressure drop & psi & 17 \\
\hline Thrust & $\mathrm{lb}$ & 16,000 & Oxidizer tank pressure & psia & 170 \\
\hline \multicolumn{3}{|l|}{ Nominal total multiple-firing } & \multicolumn{3}{|l|}{ Total oxidizer weight ( $300 \mathrm{~s}$ duration } \\
\hline duration & s & 300 & for 3 engines, plus $1 \%$ residual) & lb & 27,950 \\
\hline \multirow{2}{*}{\multicolumn{3}{|c|}{ Specific impulse }} & \multicolumn{3}{|l|}{ Oxidizer tank volume (including $3 \%$} \\
\hline & & & ullage volume) & $\mathrm{tt}^{3}$ & 305 \\
\hline Density & $\mathrm{lb} / \mathrm{tt}^{3}$ & 94.16 & \multicolumn{3}{|l|}{ Pressurant (helium) flow rate } \\
\hline Flow rate & $\mathrm{lb} / \mathrm{s}$ & 30.78 & \multicolumn{3}{|l|}{ (assuming tank gas temperature } \\
\hline \multicolumn{3}{|l|}{ Fuel $\mathrm{LH}_{2}$ : } & $\left.400^{\circ} \mathrm{R}\right)$ & $\mathrm{lb} / \mathrm{s}$ & 0.1555 \\
\hline Density & $\mathrm{lb} / \mathrm{ft}^{3}$ & 4.42 & \multicolumn{3}{|l|}{ Total pressurant weight (including } \\
\hline Flow rate & $\mathrm{lb} / \mathrm{s}$ & 5.13 & \multicolumn{3}{|l|}{ other requirements in the system) } \\
\hline Mixture ratio & $\mathrm{O} / \mathrm{F}$ & 6 & \multicolumn{3}{|l|}{ (assume storage bottle final } \\
\hline \multicolumn{3}{|c|}{ Thrust chamber (solid wall film cooled by fuel and } & pressure 350 psi, plus $2 \%$ reserve) & $\mathrm{lb}$ & 60 \\
\hline \multicolumn{3}{|c|}{ radiation cooled on nozzle extension): } & \\
\hline Thrust & $\mathrm{lb}$ & 16,000 & (assume $200^{\circ} \mathrm{R}$ storage & & \\
\hline Specific impulse & s & 446 & temperature, including $3 \%$ ullage & & \\
\hline Injector end pressure & psia & 110 & volume) & $\mathrm{ft}^{3}$ & 7.35 \\
\hline Nozzle stagnation pressure & psia & 100 & Pressurant storage tank, initial & & \\
\hline Oxidizer flow rate & $\mathrm{lb} / \mathrm{s}$ & 30.78 & pressure & psia & 4,500 \\
\hline Fuel flow rate & $\mathrm{lb} / \mathrm{s}$ & 5.13 & \multicolumn{3}{|c|}{ Fuel side (pressurized by heated hydrogen) } \\
\hline Mixture ratio & $\mathrm{O} / \mathrm{F}$ & 6 & Injector pressure drop & psi & 25 \\
\hline$c^{*}$ efficiency & $\%$ & 98 & Inlet manifold pressure drop & psi & 10 \\
\hline$c^{*}$ & $\mathrm{ft} / \mathrm{s}$ & 7,910 & Main valve pressure drop & psi & 10 \\
\hline $\mathrm{C}_{f}$ efficiency & $\%$ & 102 & Line pressure drop & psi & 5 \\
\hline$C_{f}$ & & 1.817 & Fuel tank pressure & psia & 160 \\
\hline Contraction ratio & $A_{c} / A_{t}$ & 2 & Total fuel weight ( $300 \mathrm{~s}$ duration for & & \\
\hline Expansion ratio & $A_{e} / A_{t}$ & 35 & 3 engines, plus $1 \%$ residual) & $\mathrm{lb}$ & 4,660 \\
\hline Throat area $A_{t}$ & in 2 & 88 & Fuel tank volume (including $3 \%$ & & \\
\hline$L^{*}$ & in. & 28 & ullage volume) & $t^{3}$ & 1,087 \\
\hline Nozzle contour & & $70 \%$ bell & Pressurant (hydrogen) flow rate & & \\
\hline \multicolumn{3}{|l|}{ Thrust vector control: } & (assuming tank vapor temperature & & \\
\hline Minimum acceleration & $\mathrm{rad} / \mathrm{s}^{2}$ & 2 & $\left.300^{\circ} \mathrm{R}\right)$ & $\mathrm{lb} / \mathrm{s}$ & 0.346 \\
\hline Maximum velocity & $\operatorname{deg} / \mathrm{s}$ & 15 & \multirow{2}{*}{\multicolumn{3}{|c|}{$\begin{array}{l}\text { Total pressurant weight (assuming } \\
\text { storace bottle final pressure } 350\end{array}$}} \\
\hline Displacement & $\operatorname{deg}$ & \pm 7 & & & \\
\hline \multicolumn{3}{|c|}{ Oxidizer side (pressurized by heated helium): } & psia, plus $4 \%$ reserve) & $\mathrm{lb}$ & 108 \\
\hline Injector pressure drop & psi & 25 & \multicolumn{3}{|l|}{ Pressurant storage tank, volume } \\
\hline Oxidizer dome pressure drop & psi & 5 & (liquid hydrogen including $3 \%$ ullage & & \\
\hline Main valve pressure drop & psi & 8 & volume) & $\mathrm{H}^{3}$ & 25.2 \\
\hline Line pressure drop & psi & 5 & Pressurant storage tank, pressure & psia & 350 \\
\hline
\end{tabular}



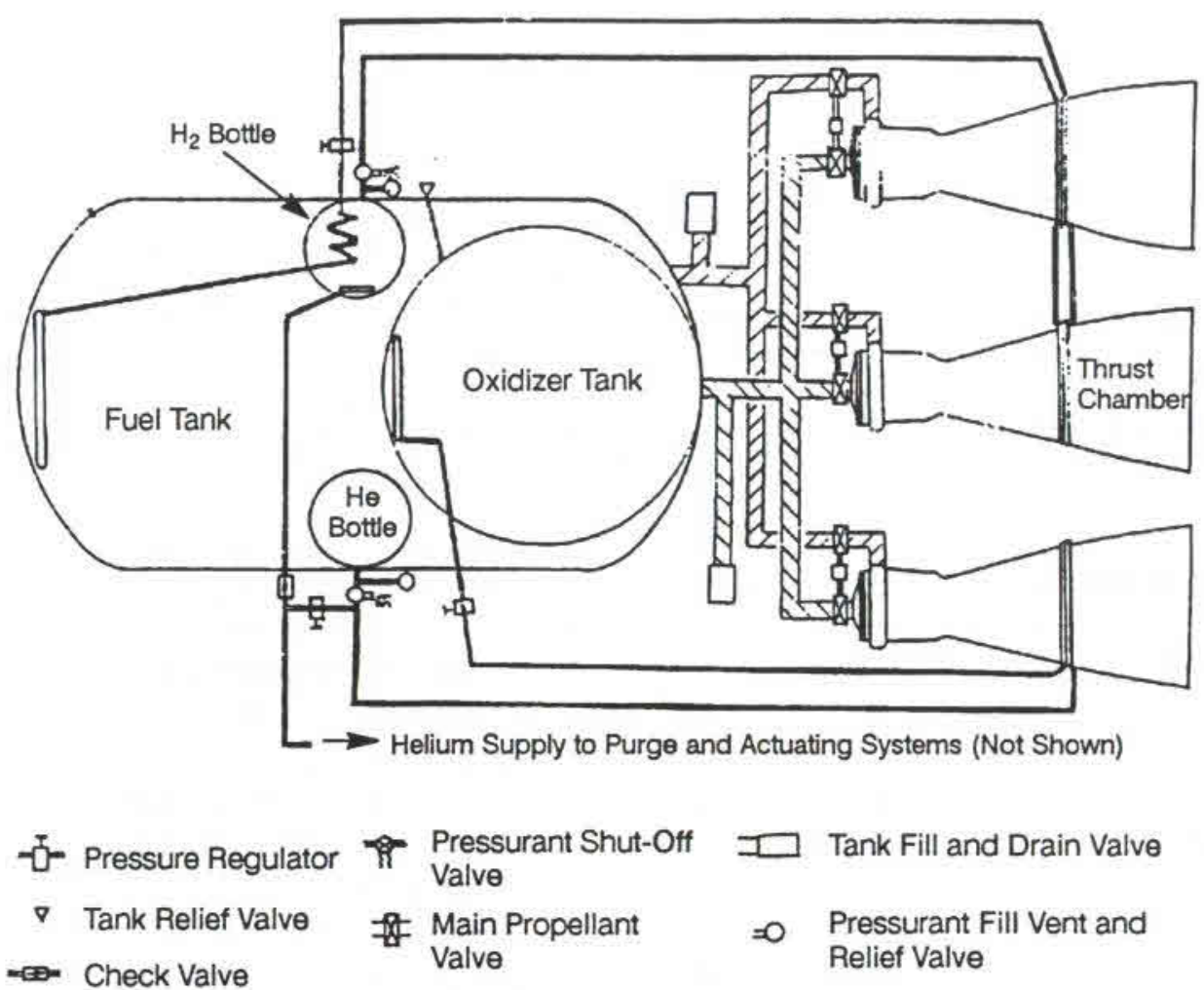

Fig. 3-6 A-3 Stage engine-system schematic diagram.

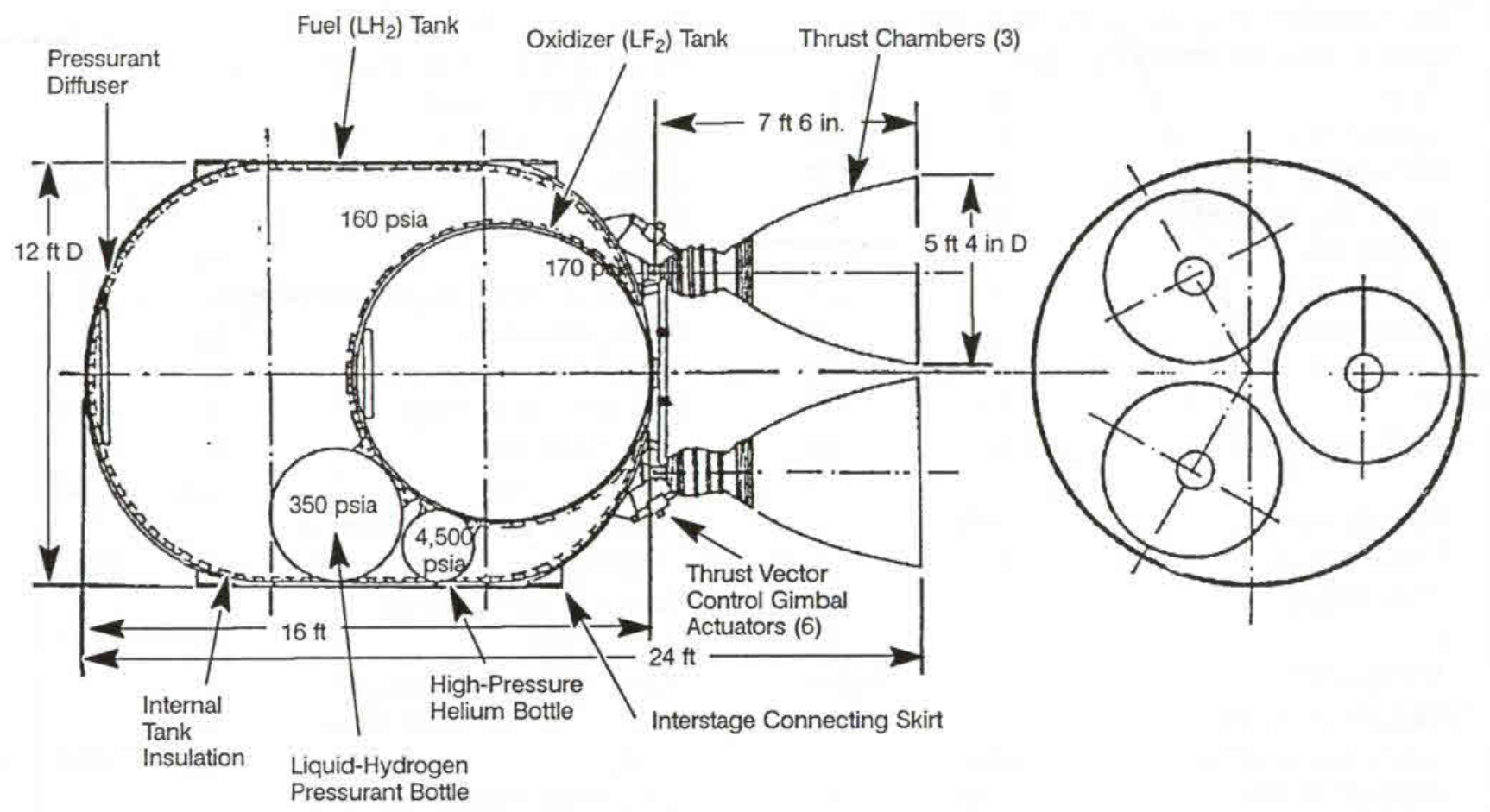

Fig. 3-7 Preliminary layout of A-3 Stage propulsion system. 
Table 3-5 A-4 Stage engine operating parameters for vacuum conditions.

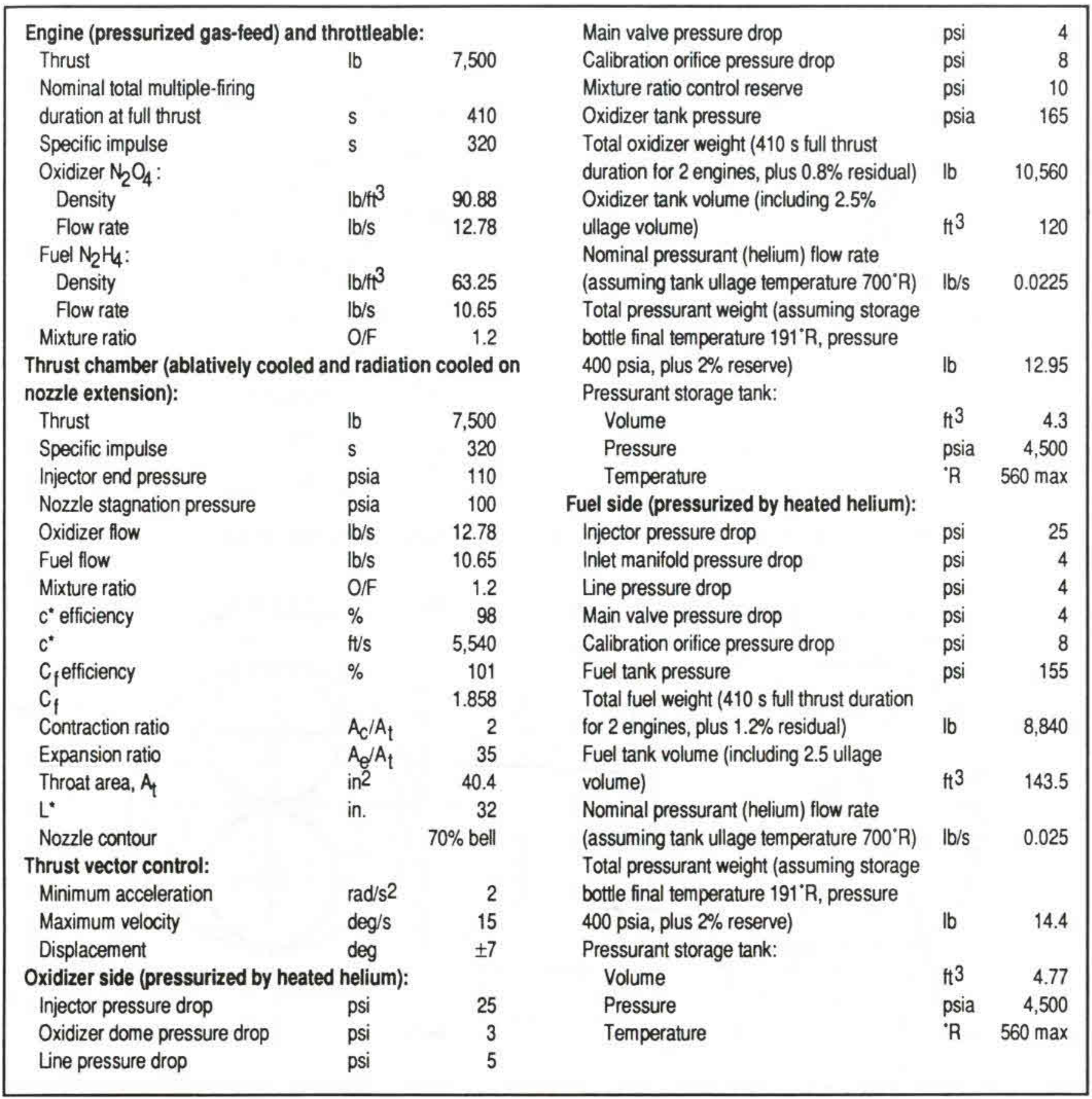

Start

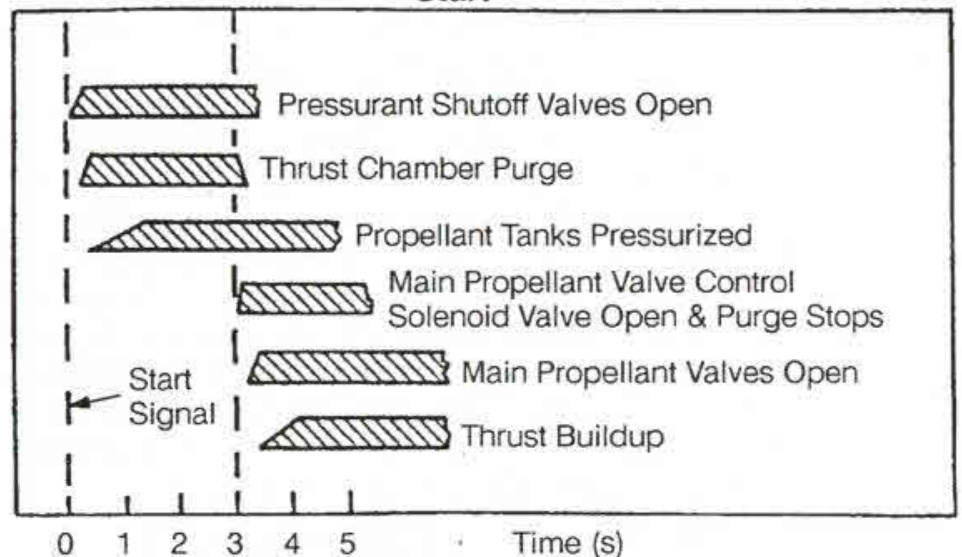

Cutoff

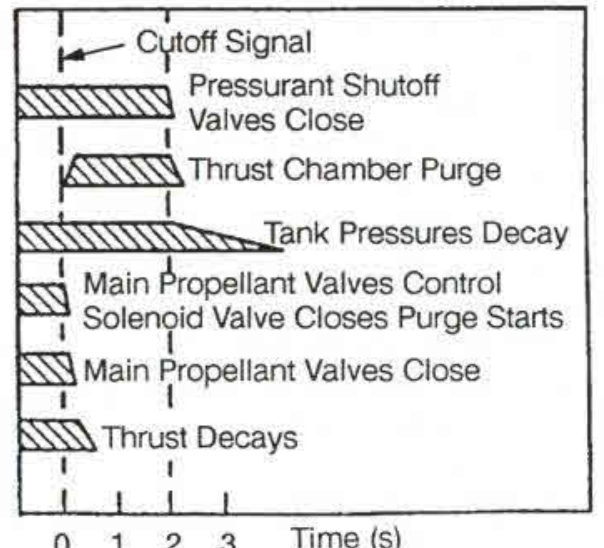

Time (s)

Fig. 3-8 A-3 Stage engine and propulsion system operational sequence. 


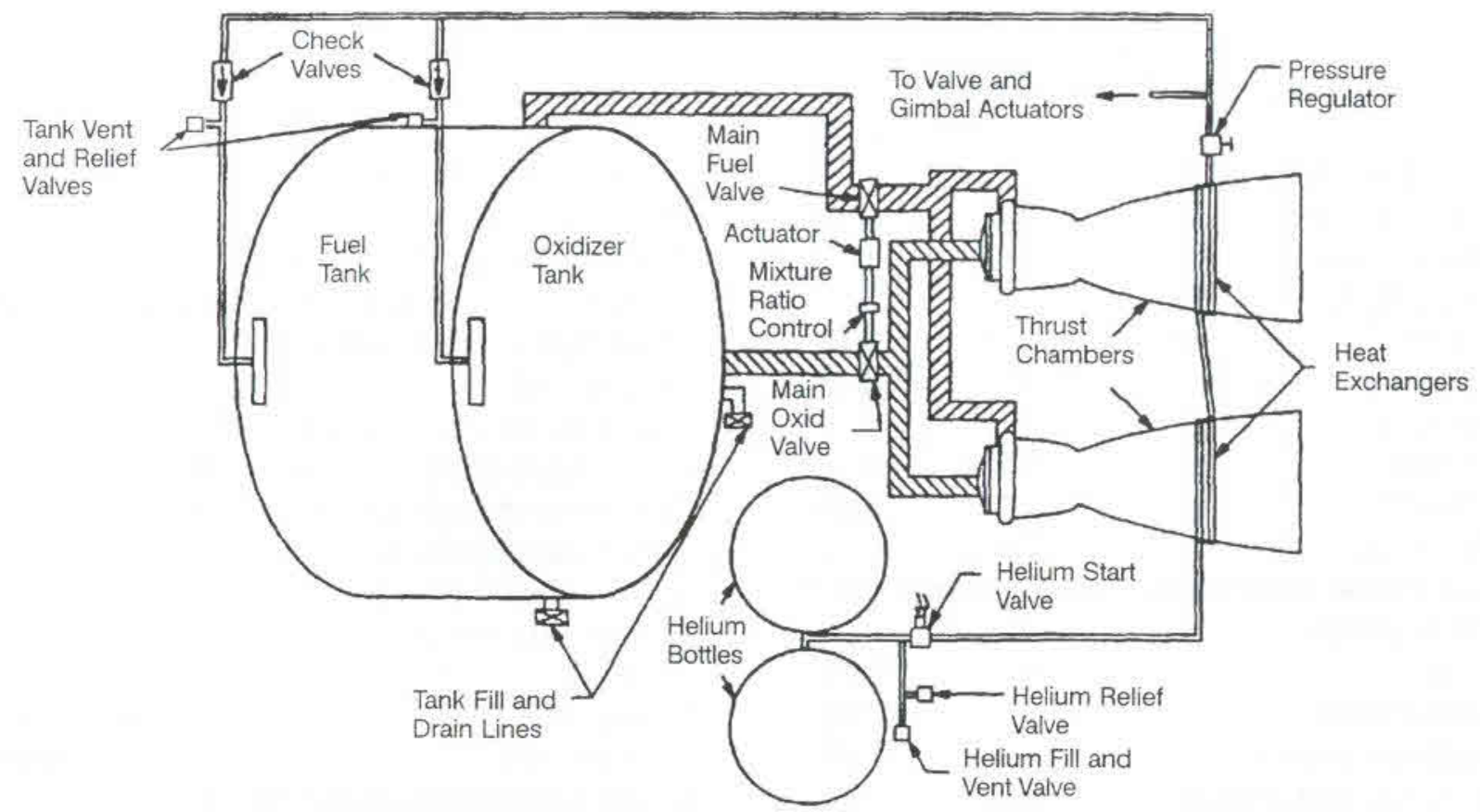

Fig. 3-9 A-4 Stage engine and propulsion system schematic diagram.

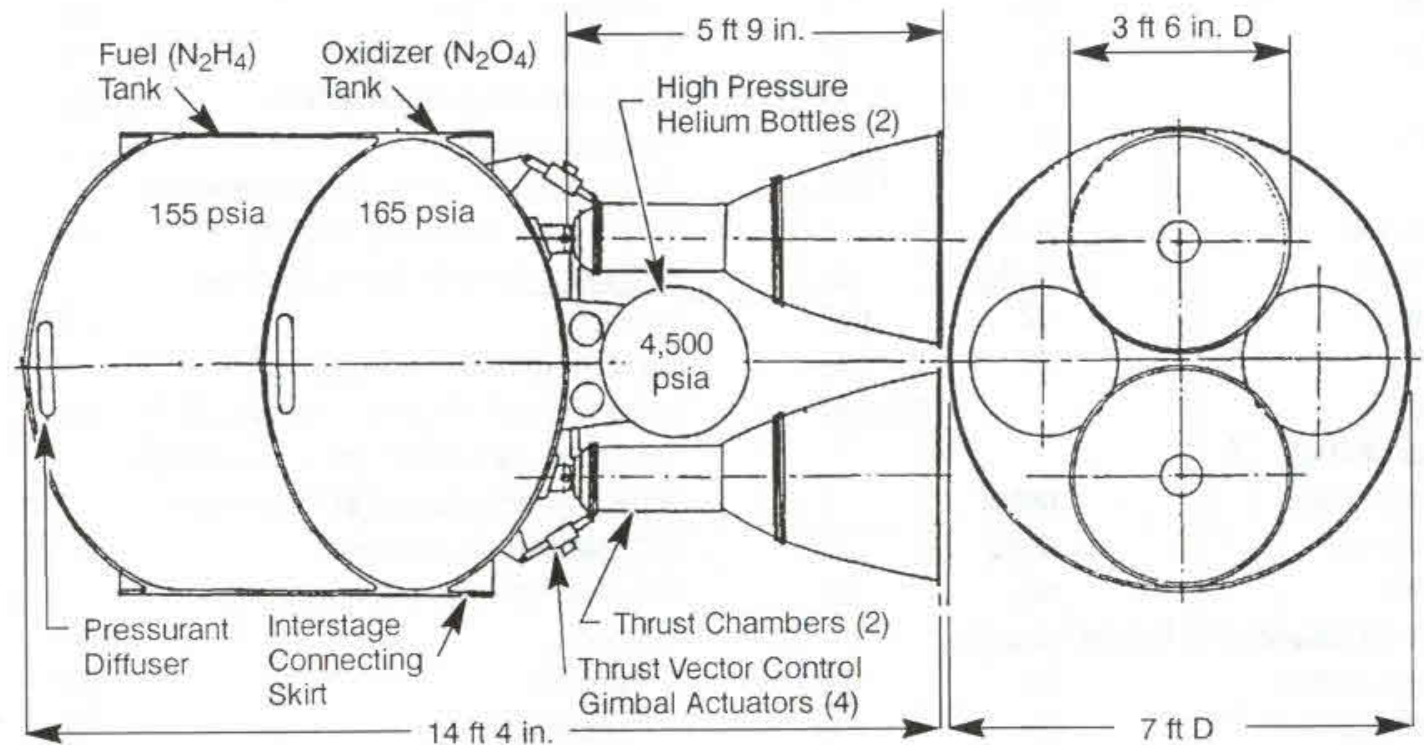

Fig. 3-10 Preliminary layout of A-4 Stage propulsion system.

than $\mathrm{N}_{2} \mathrm{O}_{4} / \mathrm{N}_{2} \mathrm{H}_{4}$, but $\mathrm{CIF}_{3}$ requires special design provisions for handling because of its thermal characteristics. For this reason, $\mathrm{N}_{2} \mathrm{O}_{4} / \mathrm{N}_{2} \mathrm{H}_{4}$ was chosen for the A-4 engine. $\mathrm{N}_{2} \mathrm{O}_{4} / \mathrm{N}_{2} \mathrm{H}_{4}$ has performance comparable to $\mathrm{LO}_{2} / \mathrm{RP}-1$ 's.

Teflon and Teflon 100X can be used as seal material in the A-4 engine system. Although Kel- $\mathrm{F}$ is a satisfactory material for use with $\mathrm{N}_{2} \mathrm{H}_{4}$, it degrades after short-term service in $\mathrm{N}_{2} \mathrm{O}_{4}$. Most series 300 stainless steels, aluminum alloys, nickel, and nickel-base brazing alloys can be used as construction materials.

\section{General Engine System}

The A-4 engine is a multiple-start, variable-thrust, gimballed, bipropellant system. The thrust-chamber assembly employs ablative and radiation cooling and undergoes hypergolic ignition. This engine system links two thrust chambers to one propellant-feed system and one set of propellant controls. The propellants are fed by pressurants directly from the propellant tanks through the main propellant valves to thrust-chamber inlets. Gaseous helium supplied from high-pressure bottles pressurizes both tanks. The pressurant is heated in heat exchangers, located at the thrust-chamber nozzle extensions before expansion through a pressure regulator and transferred to the propellant tanks. Helium gas also operates the main valves and the gimbal actuators.

Table 3-5 gives A-4 engine operating parameters at vacuum condition. Figure 3-9 shows an engine and propulsion system schematic diagram. 
Start

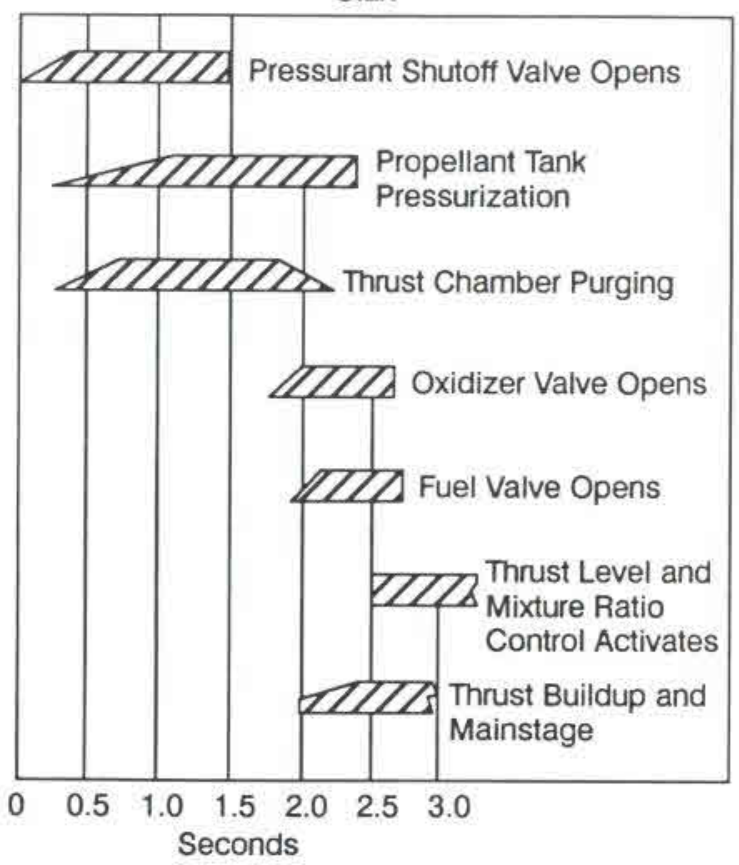

Shutdown

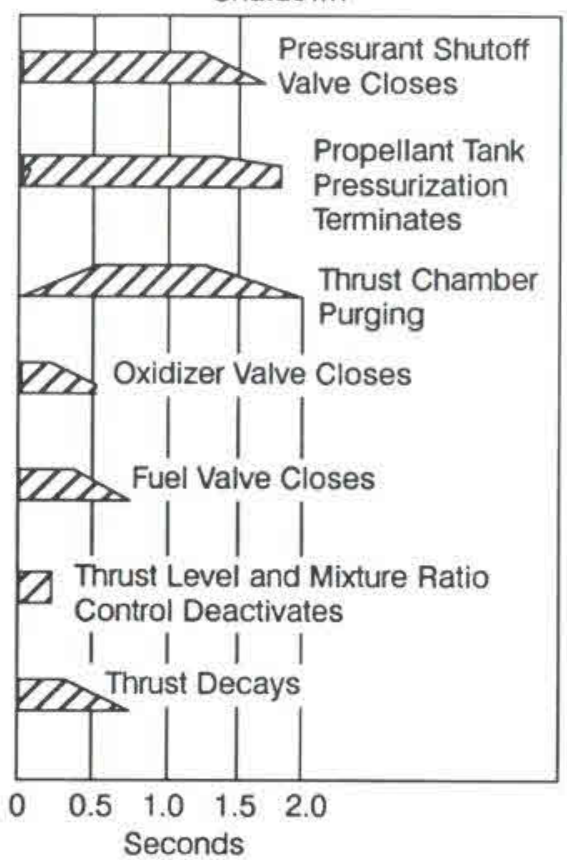

Fig. 3-11 A-4 Stage engine operational sequence.

The engine gimbal blocks are fastened to thrust mounts attached to the aft end of the oxidizer tank. The fuel tank is attached forward of the oxidizer tank to form an integral vehicle structure. As in the A-3 system, the thrust loads are transmitted to the payload through the pressure-stabilized tank assembly. The propellant ducts between fuel tank and engine systems are routed outboard and covered by fairings for protection against aerodynamic heating and for lower air resistance during first-stage boost.

Both throttling and propellant-utilization control are achieved by varying the degree of opening of both propellant valves. The positions of valves are controlled by the vehicle guidance system in conjunction with a vehicle propellant-quantity measuring system. Gimballing the thrust chambers applies TVC. The basic single engine weighs approximately $150 \mathrm{lb}$ dry and $170 \mathrm{lb}$ at burnout. It has a cylindrical space envelope of $3 \mathrm{ft} 6 \mathrm{in}$. in diam by $5 \mathrm{ft} 9 \mathrm{in}$. in length. The complete propulsion system (including the two engines and the tanks) weighs approximately $725 \mathrm{lb}$ dry, 19,649 lb wet, and $795 \mathrm{lb}$ at burnout. Figure 3-10 shows the preliminary design layout of the A-4 propulsion system.

Note that for the A-3 and A-4 engines, a slightly smaller nozzle expansion area ratio has been specified than for the A-2. Although all three upper stages operate in vacuum and can use the largest practical expansion area ratio for best performance, other considerations influence the ratio actually chosen.

\section{System Operation}

The propulsion system has been designed to start automatically upon a signal from the guidance system. During main-stage operation, engine's thrust level and mixture ratio will be controlled continuously through the engine-control package by the guidance and propellant-utilization systems. A guidance signal shuts the engine down. The propulsion system can restart an indefinite number of times. It can be operated at any level between $10 \%$ and full thrust. Figure 3-11 shows the operational sequence of the A-4 Stage engine. 